\title{
LAZER, SAÚDE COLETIVA E CONSUMO DE DROGAS
}

Recebido em: $28 / 12 / 2014$

Aceito em: 18/06/2015

Heitor Martins Pasquim ${ }^{1}$

Cássia Baldini Soares ${ }^{2}$

Universidade de São Paulo

São Paulo - SP - Brasil

RESUMO: O objeto desta reflexão é a potencialidade pedagógica do lazer no contexto do cuidado voltado a consumidores de substâncias psicoativas. Neste ensaio se objetiva retomar a perspectiva crítica do lazer e a perspectiva da saúde coletiva como potentes para explicar e intervir na problemática do consumo de drogas na atualidade. Toma-se o lazer a partir do modo de produção capitalista e o consumo de drogas a partir do modelo teórico da determinação social da saúde. Por fim, propõe-se uma prática conscientemente classista do lazer como alternativa ao lazer viciado.

PALAVRAS CHAVE: Atividades de Lazer. Saúde Pública. Usuários de Drogas.

\section{LEISURE, COLLECTIVE HEALTH AND DRUG COMSUPTION}

ABSTRACT: The subject matter of this article is the pedagogical potenciality of leisure in the context of care aimed at consumers of psychoactive substances. This essay aims to resume the critical perspective of leisure and the perspective of collective health as potent to explain and act towards the problem of drug consumption today. The leisure is taken from the capitalist mode of production and drug consumption is taken from the theoretical model of social determination of health. Finally, the article proposes a classconscious practice of leisure as an alternative to addicted leisure.

KEYWORDS: Leisure Activities. Public Health. Drug Users.

1 Doutorando em Cuidados em Saúde na Universidade de São Paulo.

2 Professora Livre-Docente da Universidade de São Paulo, Escola de Enfermagem.

Licere, Belo Horizonte, v.18, n.2, jun/2015 
"Nunca mais ladrões nem mendigos: somos os dirigentes"

Anton Makarenko

Chomsky (1999) alerta que a guerra contra (certas) drogas, para além de objeto de interesse econômico e disputa por mercado de grupos poderosos, consiste em instrumento de controle da população. Internacionalmente, essa guerra oferece argumento para intervenções militares ao redor do mundo e, internamente aos países, proporciona distração da população. Para o autor a ameaça representada pelos traficantes de drogas, na atualidade, é um dos substitutos do que ele denominou “Império do Mal”, representação contra a qual Estados Unidos e União Soviética lutavam, ou melhor, imagem que utilizavam para aterrorizar, com os crimes do império do outro, a própria população durante a Guerra Fria.

Para Zaccone (2007) vários custos sociais associados às drogas, como a violência e o tráfico, são na verdade oriundos da política proibicionista adotada pelo Estado para contornar a questão. As práticas da guerra contra as drogas ilícitas são desumanas e ocultam suas verdadeiras funções: punir os pobres, ou melhor, os "estranhos da era do consumo" - recusados como trabalhadores e estimulados como consumidores. Apesar de haver consumo de drogas em todas as classes sociais, as consequências da guerra contra as drogas são mais alarmantes nas frações da classe trabalhadora inseridas em empregos, cujos trabalhos são manuais e de menor valor frente à divisão social e técnica do trabalho.

O mesmo autor afirma que o sistema penal exercita poder de vigilância destacadamente nas áreas carentes de instituições e recursos, não apenas reprimindo a circulação e o consumo de substâncias ilícitas. A pretexto de reprimir a apologia ao narcotráfico, volta-se para o controle e encarceramento das "classes perigosas", Licere, Belo Horizonte, v.18, n.2, jun/2015 
restringindo a liberdade, como na proibição dos bailes funks e na imposição de horários de entrada e saída (ZACCONE, 2007).

Para legitimar socialmente esse controle, dissemina-se a ideologia de que o consumo de drogas é resultado da ociosidade no tempo livre do trabalho. Atualmente, com a desintegração neoliberal dos direitos sociais, o lazer é colocado, nas políticas de estado, de forma residual e subordinada à agenda da segurança, como política de manejo social do risco focada na ocupação do tempo, entendido como instrumento contra as substâncias psicoativas (MASCARENHAS, 2005). Dai decorrem os projetos de esporte e lazer com a expectativa de resgatar os jovens das drogas.

Contra esse pretexto que coloca o consumo de drogas como resultado do lazer/tempo livre, argumenta-se que apesar das substâncias psicoativas serem consumidas também em situações de vivência do lazer, o consumo de substâncias não é consequência do tempo de não-trabalho (DUMAZEDIER, 2003).

Entretanto, tal reflexão não alcança os cursos de graduação que formam trabalhadores que eventualmente poderão se envolver com políticas, práticas e ações voltadas à problemática do consumo de drogas. Não alcança também os serviços de atenção à saúde.

O lazer, originado na sociologia do trabalho, é tomado neste artigo como uma das intervenções esperadas em serviços de saúde mental, como parte dos projetos terapêuticos voltados aos consumidores de substâncias psicoativas.

O pressuposto deste ensaio é que existe consonância teórico-metodológica entre a forma de conceber o lazer dos consumidores de drogas - a partir do modo de produção capitalista - e a forma de conceber o consumo prejudicial de drogas - por meio da 
determinação social da saúde -, ambas coerentes com o materialismo histórico e dialético.

Mesmo que práticas educativas orientadas pelo prazer não constituam novidade no SUS, o lazer, coerente com o projeto de emancipação humana, segue como desafio a ser consolidado no cuidado voltado para consumidores de drogas. Busca-se neste artigo a reflexão sobre a potencialidade pedagógica do lazer no contexto do cuidado voltado a consumidores de substâncias psicoativas.

\section{Desnaturalizando o Lazer}

Para entender o lazer é necessário desnaturalizá-lo. O lazer nem sempre esteve presente na história da humanidade, embora em nossos dias seja reconhecido como direito social. A prática social do lazer foi historicamente construída na complementaridade do tempo de trabalho alienado, a partir da industrialização e urbanização capitalistas. Antes disso, as atividades lúdicas não estavam claramente separadas dos compromissos sociais, em especial as atividades laborais (MASCARENHAS, 2000).

Para Peixoto (2011), a explicação para a produção histórica do tempo livre do trabalho explorado, e todas as políticas e os projetos voltados para aumentar, diminuir ou preencher esse tempo, está no conflito de interesses que determinam a luta de classes no seio do capitalismo. Nesta direção, assume a centralidade para a compreensão da problemática do lazer, a análise do "modo de produção da existência".

Nesse sentido, é no início do século XX que os trabalhadores arrancaram da burguesia uma progressiva redução da jornada de trabalho, como resultado das lutas que visavam melhores condições de vida. A classe trabalhadora reivindicava a redução da 
jornada de trabalho e consequentemente o aumento do tempo de não-trabalho. O lazer se constrói então quando se articula um projeto de formação humana que pretende organizar o tempo disponível dos trabalhadores, ou seja, se origina da organização das práticas de controle do tempo livre do trabalho (MASCARENHAS, 2000).

O tempo social foi assim reconfigurado. O tempo de não-trabalho foi preenchido com a introdução de atividades ligadas essencialmente à acumulação de capital, contribuindo para a reposição da força de trabalho, nunca chegando de fato a se constituir, para a maioria da população, um tempo para diversão, descanso e desenvolvimento humano (MASCARENHAS, 2012). Esse é o processo por meio do qual o tempo livre do trabalho vai sendo progressivamente incorporado ao processo de valorização do capital, comodificando-se.

Pode-se identificar no estabelecimento do lazer também outro processo inerente ao modo de produção. Se antes o lazer estava mais diretamente ligado à reprodução da força de trabalho, assumindo transitoriamente a forma de salário indireto, em nossos dias o lazer está mais claramente subordinado ao próprio capital, assumindo a forma mercadoria (MASCARENHAS, 2012), fabricada sob relações capitalistas e assegurando a exploração de uma classe pela outra.

Segundo Mascarenhas (2004), daí decorrem várias mudanças que centram especial atenção na capacidade de oferta de um tempo que apesar de curto, fragmentado e descontínuo, deve ser capaz de produzir prazer instantâneo, intenso, excitado e quiçá compulsivo.

Se for verdade que o lazer não é sinônimo de tempo livre, é também verdade que ele precisa de tempo livre de trabalho. Todavia, para uma população cuja desigualdade entre classes é gritante, não basta haver mais tempo de não-trabalho. Aliás, como afirma Licere, Belo Horizonte, v.18, n.2, jun/2015 
Taffarel (2012), o tempo livre do trabalho é diferente de tempo de escassez e de incerteza, que é produzido pelo desemprego estrutural, pelo trabalho precoce e pelas circunstâncias que exigem ocupar-se de atividades que garantam apenas a sobrevivência.

Além disso, o desenvolvimento da mercadoria lazer, associado a valores da sociedade contemporânea e à produção de consumo (MARCHESE, VILELA JR, MACHADO, 2011), trouxe consigo o esvaziamento de qualquer conteúdo humanizador que o tempo livre do trabalho poderia guardar (MASCARENHAS, 2005). Consequentemente, é garantido à classe trabalhadora um lazer pobre, do ponto de vista do mercado, e burocratizado, do ponto de vista da emancipação humana.

Segundo Aquino e Cavalcanti (2004), o lazer passou a fazer parte do vocabulário da reforma psiquiátrica brasileira, a partir das denúncias sobre o abandono terapêutico do modelo asilar. A proteção e os direitos das pessoas portadoras de transtornos mentais e o redirecionamento do modelo assistencial em saúde mental teriam trazido consigo o lazer. Neste caso, o lazer é considerado contrário ao "ócio forçado", descrito por Aquino e Cavalcanti (2004), por referência ao modelo asilar.

Todavia, a prática de jogos com bola, tabuleiro ou cartas, os passeios para praia, a recreação, o bilhar, os corais, as cavalgadas e a leitura já existiam nos manicômios após a reforma de Phillippe Pinel no século XIX, de forma improvisada ou prescrita por médicos. Inclusive esse era o meio ideal de distração para o tratamento moral (PESSOTTI, 1996). Como exemplo pode-se tomar as imagens do documentário "Em nome da razão", feito em 1979 no Manicômio de Barbacena, que mostram vivências de lazer, como a música dançada no pátio, as canções cantadas coletivamente atrás das 
celas e o parquinho. Ou seja, um determinado tipo de lazer já existia antes da Lei Paulo Delgado ( $n^{\circ} 10.216$, de 6 de abril de 2001) e já existia mesmo no modelo manicomial.

O lazer hoje toma dois formatos complementares na saúde mental: como parte da ambiência (lazer/ espaço) e como lazer assistido (lazer/ tempo).

- Ambiência é a organização do espaço físico, sendo que a institucionalização do lazer nos serviços de saúde mental é parte dessa ambiência. O lazer institucionalizado pode ser um sofá em uma sala de $\mathrm{TV}$, uma mesa de ping-pong, uma quadra de futebol no fundo da unidade de saúde ou uma biblioteca bem iluminada, ou seja, coisas fixas dentro da unidade de saúde. Os serviços voltados a consumidores de drogas não apresentam diretrizes para uma ambiência diferente de outras unidades de saúde mental, simplesmente repetem a forma dos serviços criados para indivíduos com sofrimento relacionados a problemas de saúde mental;

- Lazer assistido é o preenchimento ativo do tempo de não-trabalho, portanto o lazer assume a forma de atividades práticas. Normalmente é chamado de "lazer assistido" porque é um lazer tutelado e inclusivo para o usuário do serviço. No caso dos serviços voltados para consumidores de drogas, ele tem o papel de mais um "remédio" ou obrigação terapêutica que controla o indivíduo propenso a um consumo problemático de drogas, o que exige práticas de reforço positivo, e sugere que os sujeitos deveriam ser atraídos para uma substituição química, pela qual se trocam drogas psicoativas por substâncias naturais produzidas pelo corpo em movimento, como a endorfina e a dopamina. 
Pressupõe-se aqui que tal lazer, visto como humanizado em si mesmo, sustenta projetos manicomiais e proibicionistas. As práticas hegemônicas de lazer na saúde mental, em especial aquelas voltadas para consumidores de drogas, não respondem às expectativas emancipatórias que advogamos, e por isso pode ser chamado de lazer viciado.

Destaca-se que a ação educativa de lazer é possível não só na escola, mas também no tempo não-escolar. Para isso deve-se dissociar o lazer de recreação, prática sem planejamento ou prática pela prática. As propostas pedagógicas que incluem o lazer podem levar em conta os diferentes processos e trajetórias do consumo de drogas. O lazer é uma atividade estruturada que pode favorecer transformações, desde que articulada aos problemas vividos pelos participantes (MASCARENHAS, 2000), neste caso, consumidores de drogas .

Para Mészáros (2008), a ação educativa tampouco pode se esgotar na negação do cotidiano, senão produzir uma "contra-internalização" conscientemente classista, de contraposição da internalização de ideologia que, hoje, legitima a posição que as classes ocupam na hierarquia social, bem como as expectativas socialmente estabelecidas para adequação de suas condutas.

\section{Sobre a Noção do Risco}

As recomendações, que advém das diretrizes atuais que orientam o lazer nos serviços de saúde mental, não apenas estabelecem o seu oferecimento, mas restringem as atividades (práticas) do lazer às ações preventivas e estão vinculadas à epidemiologia do risco.

Neste caso, a Política para a Atenção Integral a Usuários de Álcool e Outras Drogas identifica a atividade recreativa como fator de proteção para o uso de drogas Licere, Belo Horizonte, v.18, n.2, jun/2015 
(BRASIL, 2003). O fator de proteção assume ali a mesma função de associação positiva do risco. Já a Política Nacional sobre Drogas define que a prática de esportes e o lazer devem ser garantidos a partir de ações preventivas (BRASIL, 2005).

O conceito "risco" está presente em quase todas as diretrizes oficiais - da Constituição Federal Brasileira ao Sistema Nacional de Políticas Públicas sobre Drogas - e precisa ser compreendido.

Entretanto, no lugar da noção do risco, toma-se aqui a determinação social da saúde, como fundamento para o entendimento do consumo prejudicial de drogas (SOARES, 2007), a partir do campo da saúde coletiva.

Segundo Breilh (2010), o modo de ver a saúde na perspectiva da saúde coletiva é contra hegemônico, pois é diferente das formas utilizadas pelas postulações morais e intelectuais do neoliberalismo na atualidade. Ao abordar a saúde como um problema coletivo, compreende-se a necessidade de um paradigma interpretativo que possibilite superar a visão linear e reducionista da saúde, como um efeito mórbido de causas sem complexidade (BREILH, 2006).

A determinação social por sua vez não deve ser confundida com a associação empirista entre condições de saúde e fatores sociais (NOGUEIRA, 2010). Pesquisas, que buscaram fatores de proteção e de risco, catalogaram positivamente maiores consumos de drogas associados a "lazer aborrecido" (PONDÉ, CAROSO, 2003) ou com atividades de lazer como "namorar", “sair com amigos”, “ouvir música”, "assistir televisão" (PRATTA, SANTOS, 2007), ou ainda com "andar de bicicleta" (FERREIRA, FONTE, 2006).

A determinação social tampouco propõe associações multicausais como na forma da tríade - tipo de substância, indivíduo e contexto social - proposta por Romera Licere, Belo Horizonte, v.18, n.2, jun/2015 
(2014), para compreensão das vivências do lazer e consumo de drogas lícitas e ilícitas. Romera e Marcellino (2010) opõem-se formalmente à fragmentação que desconfigura a natureza social do lazer e das drogas. Todavia, na proposta multifatorial dos autores, o desequilíbrio, em qualquer dos fatores, geraria o abuso ou no mínimo o risco de recaída. Por consequência, as propostas de intervenção em saúde de associação causal ou multicausal tomam como referência as ações preventivas. Assim, o lazer é tomado pelos autores como mais um "determinante" social para o consumo de drogas, ou seja, como uma correlação causal entre variáveis sociais, e não como parte do processo e modo histórico estruturado.

Soares (2007) discorda de tal perspectiva que pretende estabelecer precocemente estratégias sobre os fatores de risco e de proteção, a partir do esforço individual de adesão a opções de vida (ditas) saudáveis. Nesse caso, o social é esvaziado de força explicativa, o que não acontece quando a questão é tratada sob o ponto de vista da saúde coletiva (SOARES et al., 2014).

Para a saúde coletiva, o desafio encontra-se no desenvolvimento de análises que exponham as relações entre o consumo de drogas e a totalidade social, desvendando as mediações que estão presentes na reprodução social da vida (SOARES, 2007). Essa maneira de ver a saúde surgiu, de forma consistente, na formação da epidemiologia social latino-americana na década de 1970 (NOGUEIRA, 2010). Todavia, já no início do século XIX, Engels (2008), na Inglaterra, observara uma clara associação entre alta mortalidade e pobreza. O autor afirmava que o capitalismo e a exploração de classe produzem pobreza, doença e morte. Nesse sentido, para tornar realidade o acesso à saúde da população não basta assistência à saúde, mas sim profundas transformações no 
modo de organização da sociedade. Essa busca por melhores condições de trabalho e de vida se associa às lutas de classe.

É incontestável a contribuição da epidemiologia dos fatores de risco para o estudo da frequência e distribuição das enfermidades nas populações. Os estudos baseados em risco possibilitaram superar o modelo de atenção centrado na demanda espontânea. Segundo Ayres (2001), o termo risco começa a integrar a epidemiologia apenas na década de 1920. O surgimento do vocábulo "risco" se deu de forma tardia em um momento em que o futuro passava a ser pensado como passível de controle. Ele destaca que conforme o conceito de "meio externo" vai se rarefazendo, o "risco" vai se adensando, o que configurou uma perspectiva mais tecnicista e pragmática. Atualmente, quando se pensa em risco, mesclam-se formas de se relacionar com o futuro e gerir o presente.

Almeida-Filho e Coutinho (2007) advertem que essa epidemiologia do risco entra em crise a partir de questões que destacam a complexidade do processo saúdedoença. Consideram ainda que investigações com complicação na modelagem podem ser construídas por meio de modelos multicausais (por exemplo, a tríade ecológica). Entretanto, esses modelos estão longe de produzir complexidade, porque neles não há qualquer hierarquia nem qualquer consideração da diversidade complexa da realidade concreta. E concluem que o conceito de risco apresenta custos técnicos, sociais e políticos que apontam para a necessidade de revisar e superar seus próprios limites.

Para Czeresnia e Albuquerque (1995), existe um paradoxo conceitual na adoção de desenhos de estudo que exigem uma comprovação experimental em situações não reprodutíveis sobre condições experimentais controladas. Toma-se a busca da verdade como uso correto do método. Dessa forma, tem-se a pretensão de superar todas as Licere, Belo Horizonte, v.18, n.2, jun/2015 
ideologias políticas e interpretações sociais, que minam o campo da cientificidade na investigação da saúde. Dizendo de outra forma, prometem a utopia da saúde perfeita, independente dos processos sociais.

Nesta perspectiva, a indeterminação do conhecimento seria transitória, segundo a qual, a predição do que vai acontecer pode ser obtida quando todas as variáveis que controlam o processo forem conhecidas e descritas em modelo linear. A linearidade decorre de uma interpretação possível do próprio método de inferência. Afinal, construir um modelo para medir o efeito de uma ou mais causas exige um processo de redução do fenômeno, que viabiliza o modelo, isolando os elementos com associação que se deseja observar. Esse processo constrói uma representação que reduz a complexidade do fenômeno. A epidemiologia cria com a noção do risco um universo paralelo, onde habitam "populações inventadas", compostas por "seres ilusórios" (CZERESNIA, ALBUQUERQUE, 1995).

Segundo Breilh (2006), embora o risco tenha se convertido na contemporaneidade numa verdadeira matriz disciplinar, que vai cada vez mais dando legitimidade a qualquer pesquisa em saúde, é também uma forma reducionista ou finalística que desfaz os vínculos entre os fenômenos epidemiológicos e os processos mais gerais.

Apesar de operar em nome do todo, a ênfase de ações que tomam centralmente a noção do risco, desmobiliza as atitudes coletivas mesmo quando partem de grupos aglutinados por risco. A gestão de risco está centrada no indivíduo, não em coletivos, comunidades, muito menos em classes sociais. O coletivo para a categoria risco toma uma forma fundamentalmente estatística. Os indivíduos são reduzidos a unidades justapostas em uma população e devem ser tratados como mensuráveis e independentes. Licere, Belo Horizonte, v.18, n.2, jun/2015 
Nesta perspectiva, perde-se de vista a existência de indivíduos concretos que vivenciam situações que lhes são dadas e que interpretam e fornecem significados aos seus comportamentos e aos dos outros (BREILH, 2006).

O risco como apoio das inferências epidemiológicas ainda é refém da doença. A prevenção, baseada na noção do risco, pode evitar a manifestação da patologia, mas não a presença reiterada da doença. De fato, as garantias retóricas projetadas por essa racionalidade não se traduzem em tranquilidade e confiança (BREILH, 2006).

Castel (2010) mostrou que a insegurança e a proteção não estão em pólos opostos aos da experiência concreta, assim a própria busca de proteção cria insegurança. Pode-se, neste sentido, traçar um paralelo com o discurso preventivista-antecipatório, descrito por Carvalho (2004), responsável por um efeito contraditório que traz uma prática persecutória aos indivíduos, diante das propostas de promoção da saúde baseadas em estratégias comportamentais. Moraes e Nascimento (2002) questionam, por exemplo, se as relações entre as patologias psíquicas comuns da atualidade não estariam associadas à estratégia de prevenção que assume dimensões de obrigação incondicional, desencadeando um efeito perverso de angústia e levando as pessoas a acreditar que estão perdendo o comando sobre a própria vida.

Além da dificuldade crescente em estar assegurado contra os riscos, parece haver uma pane e uma erosão nos sistemas de proteção. O estado capitalista opera como redutor de riscos, mas não o faz igualmente entre seus membros (CASTEL, 2010). Para Breilh (2006) o paradigma do risco é a base de uma epidemiologia sem memória e sem sonho de emancipação, sendo, portanto, um instrumento estratégico para políticas conservadoras. 
A superação da epidemiologia dos riscos se dá de forma mais estruturada na construção e desdobramentos da epidemiologia crítica (SOARES et al., 2014), que articula as formas de inserção socioeconômica de trabalho e de vida dos grupos sociais para explicar a distribuição dos problemas de saúde, que configuram um dado perfil epidemiológico. Ademais, para a epidemiologia crítica, os processos saúde-doença são contradições potenciais em forma dialética de desgastes e de fortalecimentos, e não a justaposição de fatores de risco para descrever estados de saúde.

\section{O Consumo de Drogas na Saúde Coletiva}

Para identificar o potencial do lazer é preciso ter em mente o que se almeja com o próprio cuidado em geral para os consumidores de drogas.

É de conhecimento da história, que o uso de substâncias psicoativas com a finalidade de produzir modificações nas sensações e percepções, alterando em alguma medida e temporariamente a consciência, existe desde a antiguidade e em todas as civilizações. Várias substâncias psicoativas são parte indispensável dos ritos de sociabilidade, devoção, consolo, prazer e cura. Aliás, assim como acontece com alimentos e bebidas, o consumo de substâncias psicoativas também pode assumir formas recreativas, religiosas entre outras (CARNEIRO, 2002).

Carneiro (2002) descreve os sentidos históricos dessas substâncias e a relação com os diversos saberes constituídos e difundidos, sociedade por sociedade. Assim, as necessidades, que se vinculam ao consumo de substâncias psicoativas, são constituídas socialmente em um determinado tempo-espaço e variam em razão da produção e reprodução social às quais estão referidas. 
Para Soares (2007), é na contemporaneidade que se constituiu um conjunto de novas necessidades de consumo de mercadorias, às quais se incluem as substâncias psicoativas. Segundo a autora, foi somente a partir do capitalismo que a droga passou a integrar o conjunto de mercadorias, cujo consumo responde a diferentes necessidades impostas pelo desenvolvimento das forças produtivas do sistema social.

A mercantilização das necessidades sociais tem relação direta com o sistema de produção, em que prevalece a lógica da reprodução do sistema em detrimento de outras necessidades (BARATTA, 1994). Essas necessidades de reprodução do sistema, incluindo aqui as novas formas de consumo de droga, foram chamadas por Heller (1986) como necessidades alienadas.

A inscrição de necessidades em um determinado momento da história se integra como parte da sociabilidade, naturalizando-se nas relações estabelecidas entre os indivíduos. No entanto, à medida que ocorrem mudanças no modo de vida, as necessidades também se transformam e se sobrepõem àquelas mais valorizadas no passado. Dessa forma, todas as necessidades na sociedade contemporânea são influenciadas pelo modo de produção capitalista e as relações sociais que o constituem (VIANA, 2007).

Vive-se em um mundo valorativo, em que as necessidades mais valorizadas estão submetidas às necessidades do capital, outras necessidades se tornam marginais e se mantêm como valor somente para determinadas culturas de resistência (VIANA, 2007). Isso também acontece com as formas de consumir substâncias psicoativas, já que algumas são valorizadas socialmente porque respondem a necessidades do modo de produção capitalista, outras não. Destacam-se aqui algumas substâncias que amenizam os desgastes oriundos da exploração do trabalho humano. 
Na sociedade atual, a discussão sobre necessidades satisfeitas com o consumo de substâncias psicoativas foi marginalizada, já que a vertente dominante - política e ideológica - consolidou no imaginário social a máxima de que a droga é um mau a ser abolido (SOARES, 2007). Isso se traduz de forma ainda mais radical e arbitrária na divisão entre drogas lícitas e ilícitas (CARNEIRO, 2002), o que dificulta os estudos que buscam aprimorar o conhecimento para a redução de danos.

Entre esses estudos, Santos e Soares (2013) demonstram que a compreensão dos consumos prejudiciais de substâncias psicoativas vai além da reação química apontada pelo saber psiquiátrico nas classificações internacionais sobre doenças. Aliás, a ideia de uma dependência química restringe a compreensão da relação sujeito-substância aos efeitos psicoativos no corpo de um indivíduo que é considerado propenso a tal relação problemática. Conforme refere Hart (2014), essa compreensão é altamente questionável mesmo em testes de laboratório com animais.

A perspectiva dominante nos serviços de saúde mental dialoga com a racionalidade religiosa, que deposita no sujeito consumidor de droga características morais, para a qual a cura está na aceitação do "Poder Superior" e remissão dos pecados, como no método dos "12 passos" (JUNAAB, 2005) dos Alcoólatras Anônimos. A perspectiva dominante na saúde é a visão funcionalista sobre o binômio "droga" e "indivíduo vulnerável", que toma a vulnerabilidade como causa do consumo. Daí decorre a justificativa de uma prática reiterativa, que reproduz orientações previamente traçadas para um indivíduo coisificado. Nesse sentido, é fácil identificar campanhas que abordam o consumidor de drogas como uma vítima frágil, "deficiente de informação e de caráter", e também, como sujeito culpado pelo sofrimento da família e protagonista do prejuízo do estado. Essa ideia reproduz uma compreensão simplista Licere, Belo Horizonte, v.18, n.2, jun/2015 
das terapêuticas e que não leva em conta a complexidade do consumo de drogas (SANTOS, SOARES, CAMPOS, 2010).

Na saúde coletiva busca-se propor outra abordagem da relação que se constitui entre indivíduo e substância psicoativa. O consumo prejudicial seria justamente a exacerbação de um tipo programado de consumo na atualidade. Uma sociedade capitalista ideal geraria pessoas cada vez mais "viciadas" em alimentos, roupas, carros, esportes e drogas (SANTOS, SOARES, CAMPOS, 2010).

Para Santos e Soares (2013), as relações prejudiciais ou problemáticas, que as pessoas estabelecem com a mercadoria droga, devem ser entendidas como um sintoma do mal-estar que perpassa a vida nas suas diferentes conformações e se ligam às formas alienadas de satisfação de necessidades constituídas no cenário atual.

Para melhor entender o mal-estar social na atualidade é imprescindível compreender os valores que vão se constituindo no modo de produção capitalista. Segundo Viana (2007), os valores sociais dominantes são justamente os valores particularistas e inautênticos relacionados à cultura capitalista em curso. Nessa direção, Castel (2010) chama atenção para o processo de "descoletivização" e de reprodução de uma sociedade de indivíduos, produzindo não apenas mudanças no trabalho e na vida, mas frustrações, ansiedade e medo.

Felizmente, as pessoas não possuem apenas um valor tampouco uma coerência absoluta em seus valores, e sim valores conflitantes. Ademais, as variadas práticas de conformismo e de resistência não se traduzem apenas em manifestações ou atos públicos, mas estão também inscritas nos modos contraditórios de trabalhar e viver. Sendo assim, a resistência própria de cada um dos grupos sociais pode ser decodificada 
e potencializada (VIANA, 2007). Neste caso, a superação das armadilhas de reprodução de necessidades alienadas exige uma "práxis criadora".

Essa práxis criadora funciona como um mecanismo que não destitui as pessoas de sua consciência histórica e social, porque as relações que estabelece não são naturalizadas e reproduzidas acriticamente (VÁZQUEZ, 1977).

Aqui se sugere uma prática coerente com a redução de danos emancipatória (SOARES, 2007), entendendo o lazer como fonte contraditória de tensão valorativa, e como mais uma prática coerente com a luta social pela transformação radical da sociedade. Isso é diferente do viés subjetivista que busca com o lazer uma emancipação centrada na atitude, como Bacheladenski e Matiello Jr (2010) descrevem no "lazer emancipatório", no qual os sujeitos se transformam na medida em que modificam seu lazer. Afinal, a vivência de momentos solidários e participativos não gera em si mudanças estruturais. Ademais, não é possível falar em emancipação em nível individual.

Vale destacar também que os consumidores de drogas, assim como qualquer outro indivíduo, apresentam atitudes espontâneas contra os interesses do capitalismo (absenteísmo no trabalho, ocupação de espaços públicos e centrais, ruptura parcial com a moral e a ética contemporânea), atitudes insuficientes para viabilizar a emancipação humana. Todavia, nessas lutas cotidianas, a consciência da determinação social do consumo de drogas pode fazer avançar a organização e a realização de lutas emancipatórias, que apontem para o "gozo do tempo livre para uma atividade livre", como descreve Peixoto (2011).

O papel específico dos agentes de lazer não é emancipar o consumidor de drogas, senão criar as condições necessárias que reforcem as posições coletivas e Licere, Belo Horizonte, v.18, n.2, jun/2015 
subversivas dos trabalhadores que eventualmente se envolveram com o consumo de drogas, ou seja, caracterizam-se pela instituição de contra-poderes.

Por conseguinte, os temas geradores para a prática conscientemente classista de lazer não se realizam apenas na escolha da modalidade (futebol, cacuriá, capoeira ou carnaval), mas na escolha de contradições vividas pelos consumidores de drogas.

Sobressai aqui a importância da desinstitucionalização ou do desgoverno em contradição ao controle na saúde tradicional. No entanto, é difícil imaginar um tempo realmente livre de exploração e de exclusão na atualidade. Assim, não se trata apenas de estar formalmente livre para tratamento, como a diferença óbvia entre o acompanhamento em um Centro de Atenção Psicossocial - CAPS e em uma Comunidade Terapêutica. Em seu lugar, urge pensar o lazer com consumidores de drogas como uma resposta política para sujeitos em uma sociedade adoecida.

O lazer da saúde coletiva é uma prática conscientemente classista que não se submete a uma forma fixa de ambiência apenas agradável e amena, mas exige uma desinstitucionalização dos serviços de saúde, e, além disso, a apropriação do território que permita uma vivência integradora, participativa, diversa e múltipla do lazer. Tampouco se propõe a reforçar o fetiche do estado e da cidadania (VIANA, 2003 e TONET, 2005), como na proposta de "lazerania" (lazer + cidadania), de Mascarenhas (2004). Tal fetiche também alcança os serviços de saúde mental, como na busca declarada resgatar, por meio de jogos e eventos culturais, a cidadania de usuários dos serviços de saúde mental (CASSANDRI, SILVA, 2009), como se fosse possível uma luta societária que combate a exclusão social e não a exploração do homem sobre o homem ou a burocratização da ação estatal. 
O objetivo do lazer iluminado pela perspectiva emancipatória da redução de danos é o de fortalecer o bem-estar humano contra o mal estar social, permitindo ao consumidor de drogas buscar o sentido de suas próprias vivências, na tentativa de encontrar uma resposta auto gestada para a transformação de sua realidade, o que deve opor-se à unidirecionalidade e reivindica uma prática educativa dialética.

\section{Finalizando}

Neste ensaio foram retomados os pilares que vêm sendo construídos pelos que advogam a perspectiva crítica do lazer e a perspectiva teórica da saúde coletiva como potente para explicar e intervir na problemática do consumo de drogas na atualidade. A partir destas perspectivas, foram negadas as concepções que deslocam a consciência do sujeito para a droga em si, assim como as concepções que atribuem à pessoa que consome droga, características negativas ou frágeis. Em seu lugar, entende-se que o sujeito coletivo consumidor de drogas é a classe social e a droga uma mercadoria.

Ressalta-se que a prática classista do lazer não impõe contradições ao tempo livre do trabalho, assim como não tenta homogeneizar o lazer como algo que pretensamente poderia assumir uma forma plenamente solidária, rodeada pelas relações capitalistas hodiernas. Em seu lugar, evidenciam-se contradições vividas pelos consumidores de drogas e por isso podem produzir bem-estar e podem estar associadas a outras estratégias pedagógicas, que fazem refletir sobre a conscientização da determinação social do consumo de drogas.

Identifica-se aqui o lazer como parte do projeto terapêutico voltado a consumidores de drogas e não como prática isolada ou compensatória, ousando transformar práticas e serviços onde hoje predominam muros e o poder do "jaleco branco”. Neste caso, a prática conscientemente classista do lazer não está vinculada aos 
discursos de combate ao ócio e de substituição química, rompendo com o modelo aqui chamado de "lazer viciado".

Contra os projetos proibicionistas e manicomiais, é preciso animar a luta radical pela emancipação humana. Contra a racionalidade que faz propaganda de uma verdade única, manifestar contradições pode ser bastante significativo, mas o ponto principal no processo pedagógico é fazer isso de forma persistente e organizadamente classista.

\section{REFERÊNCIAS}

ALMEIDA-FILHO, N.; COUTINHO D. Causalidade, contingência, complexidade: o futuro do conceito de risco. Physis, Rio de Janeiro, v. 17, n. 1, p. 95-137, 2007.

AQUINO, M.M.B.; CAVALCANTI, M.T. Os dispositivos de lazer no contexto da reforma psiquiátrica brasileira: o Clube do Lazer Cidadania Colônia, um estudo de caso. Rev. Latinoam. Psicopat. Fund., São Paulo, v. 7, n. 4, p. 165-191, 2004.

AYRES, J.R.C.M. Risco e imponderabilidade: superação ou radicalização da sociedade disciplinar? Cad. Saúde Pública, Rio de Janeiro, v. 17, n. 6, p. 1297-1298, 2001.

BACHELADENSKI, M.S.; MATIELLO JÚNIOR, E. Contribuições do campo crítico do lazer para a promoção da saúde. Ciência \& Saúde Coletiva, Rio de Janeiro, v. 15, n. 5, p. 2569-2579, 2010.

BARATTA, A. Introdução a uma sociologia da droga. In: MESQUITA, F.; BASTOS, F.I. (Org.). Drogas e AIDS: estratégias de redução de danos. São Paulo: Hucitec, 1994. p.21-43.

BRASIL. Política Nacional sobre Drogas. Diário Oficial da República Federativa do Brasil, Brasília, 27 out. 2005. p. 9-12.

- Ministério da Saúde. Política do Ministério da Saúde para a Atenção Integral a Usuários de Álcool e Outras Drogas. Brasília: Ministério da Saúde, 2003.

BREILH, J. Epidemiologia crítica: ciência emancipadora e interculturalidade. Rio de Janeiro: Fiocruz, 2006.

Las tres ' $\mathrm{S}$ ' de la determinación de la vida: 10 tesis hacia una visión crítica de la determinación social de la vida y la salud. In: NOGUEIRA, R.P. (Org.). Determinação Social da Saúde e Reforma Sanitária. Rio de Janeiro: Cebes, 2010. p. 87-125. 
CARNEIRO, H. As necessidades humanas e o proibicionismo das drogas no século XX. Rev. Outubro IES, São Paulo, n. 6, p.115-28, 2002.

CARVALHO, S.R. As contradições da promoção à saúde em relação à produção de sujeitos e a mudança social. Ciência \& Saúde Coletiva, Rio de Janeiro, v. 9, n. 3, p. 669-678, 2004.

CASSANDRI, J.L.; SILVA, A.L.A. Contribuições da Copa da Inclusão para a consolidação do campo psicossocial. Rev. esc. Enferm, São Paulo, v. 43, n. 2, p. 384$392,2009$.

CASTEL, R. El Ascenso de las Incertidumbres: trabajo, protecciones, estatuto del individuo. Buenos Aires: Fondo de Cultura Económica, 2010.

CHOMSKY, N. O que o Tio Sam realmente Quer. Brasília: UnB, 1999.

CZERESNIA, D.; ALBUQUERQUE, M.F. Modelos de inferência causal: análise crítica da utilização da estatística na epidemiologia. Revista de Saúde Pública, São Paulo, v. 29, n. 5, p. 415-23, 1995.

DUMAZEDIER, J. As Drogas e a Revolução Social do Lazer. Licere, Belo Horizonte, v. 6, n. 2, p. 11-22, 2003.

ENGELS, F. A situação da classe trabalhadora em Inglaterra. São Paulo: Boitempo, 2008.

FERREIRA, C.; FONTE, C. O consumo de drogas e o envolvimento em actividades de lazer na adolescência. Motricidade, Portugal, v. 2, n. 3, p. 159-166, 2006.

HART, C. Um preço muito alto: a jornada de um neurocientista que desafia nossa visão sobre as drogas. Rio de Janeiro: Zahar, 2014.

HELLER, A. Teoría de las necessidades em Marx. Barcelona: Península, 1986.

JUNAAB. Os doze passos e as doze tradições. São Paulo: JUNAAB, 2005.

MARCHESE, D.; VILELA JUNIOR, G. B.; MACHADO, A. A. O lazer como possível espaço/tempo para o consumo de drogas. Licere, Belo Horizonte, v. 14, n. 4, p. 1-22, 2011.

MASCARENHAS, F. Entre o ócio e o negócio: teses acerca da anatomia do lazer. Tese (Doutorado) - Faculdade de Educação, Universidade Estadual de Campinas, Campinas, 2005.

Lazer e Grupos Sociais: concepções e método. Dissertação (Mestrado) -

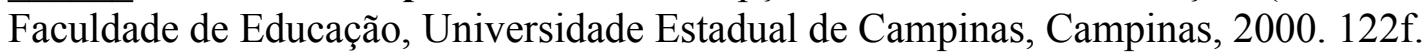

"Lazerania" também é conquista: tendências e desafios na era do mercado. Movimento, Porto Alegre, v. 10, n. 2, p. 73-90, 2004. 
MASCARENHAS, F. O lazer como Possibilidade de Intervenção nos Determinantes Sociais da Saúde. 05 julho 2012. Disponível em: https://www.youtube.com/watch?v=COPLmf7USgE. Acesso em: 28 dez. 2014.

MÉSZÁROS, I. A educação para além do capital. 2. ed. São Paulo: Boitempo, 2008.

MORAES, T. D.; NASCIMENTO, M. L. Da norma ao risco: transformações na produção de subjetividades contemporâneas. Psicologia em Estudo, v. 7, n. 1, p. 91-102, 2002.

NOGUEIRA, R.P. Repensando a determinação social da saúde. In: NOGUEIRA, R.P. (Org.). Determinação Social da Saúde e Reforma Sanitária. Rio de Janeiro: Cebes, 2010. p. 7-12.

PEIXOTO, E.M.M. Notas introdutórias sobre a teoria e as categorias centrais para a pesquisa da problemática do lazer. Revista HISTEDBR On-line, Campinas, n. especial, p. 332-346, 2011. Disponível em: http://www.histedbr.fe.unicamp.br/revista/edicoes/41e/art23_41e.pdf. Acesso em: 28 dez. 2014.

PESSOTTI, I. O século dos manicômios. São Paulo: Ed. 34, 1996.

PONDÉ, M.P.; CAROSO, C. Lazer como fator de proteção da saúde mental. Rev. Ciênc. Med., Campinas, v. 12, n. 2, p. 163-172, 2003.

PRATTA, E.M.M.; SANTOS, M.A. Lazer e Uso de Substâncias Psicoativas na Adolescência: possíveis relações. Psicologia: teoria e pesquisa, Brasília, v. 23, n. 1, p. 43-52, 2007.

ROMERA, L. As drogas e os cenários de lazer. Licere, Belo Horizonte, v. 17, n. 3, p. 303-317, 2014.

ROMERA, L.A.; MARCELLINO, N.C. Lazer e Uso de Drogas: a partir do olhar sociológico. Impulso, Piracicaba, v. 20, n. 49, p. 75-84, 2010.

SANTOS, V.E.; SOARES, C.B. O consumo de substâncias psicoativas na perspectiva da saúde coletiva: uma reflexão sobre valores sociais e fetichismo. Saúde \& Transformação Social, Florianópolis, v. 4, n. 2, p. 38-54, 2013.

SANTOS, V.E.; SOARES, C.B.; CAMPOS, C.M.S. Redução de danos: análise das concepções que orientam as práticas no Brasil. Physis, Rio de Janeiro, v. 20, n. 3, p. 995-1015, 2010.

SOARES, C.B. Consumo contemporâneo de drogas e juventude: a construção do objeto na perspectiva da saúde coletiva. Tese (Livre docência) - Escola de Enfermagem, Universidade de São Paulo, São Paulo, 2007.

SOARES, C.B. et al. Marxismo, trabalho e classes sociais: epidemiologia crítica como instrumento da saúde coletiva. In: CARVALHEIRO, J.R.; HEIMANN, L.S.; 
DERBLIC, M. (Org). O social na epidemiologia: um legado de Cecília Donnangelo. São Paulo: Instituto de Saúde, 2014.

TAFFAREL, C.Z. Ocio y proyecto histórico. Revista educación física y deporte, Medellín, v. 31, n. 2, p. 1081-1094, 2012.

TONET, I. Educação, Cidadania e Emancipação Humana. Ijuí: Unijuí, 2005, 256 p.

VÁZQUEZ, A.S. Filosofia da práxis. Rio de Janeiro: Paz e Terra, 1977.

VIANA, N. Estado, Democracia e Cidadania: a dinâmica da política institucional no capitalismo. Rio de Janeiro: Achiamé, 2003.

Os valores na sociedade moderna. Brasília: Thesaurus, 2007.

ZACCONE, O. Acionistas do nada: quem são os traficantes de drogas. Rio de Janeiro: Revan, 2007.

\section{Endereço dos Autores:}

Heitor Martins Pasquim

Departamento de Enfermagem em Saúde Coletiva

Universidade de São Paulo

Av. Dr. Enéas de Carvalho Aguiar, 419

São Paulo - SP - 05403-000

Endereço Eletrônico: hpasquim@gmail.com

Cássia Baldini Soares

Departamento de Enfermagem em Saúde Coletiva

Universidade de São Paulo

Av. Dr. Enéas de Carvalho Aguiar, 419

São Paulo - SP - 05403-000

Endereço Eletrônico: cassiaso@usp.br 